\title{
Key Parameters Controlling An Adsorption Process For The Selective Removal Of Arsenic From Drinking Water
}

\author{
Stéphanie Ouvrard, LSGC, 1 Rue Grandville, BP 451, 54001 Nancy Cedex, France \\ Marie-Odile Simonnot, LSGC, 1 Rue Grandville, BP 451, 54001 Nancy Cedex, France \\ Michel Sardin, LSGC, 1 Rue Grandville, BP 451, 54001 Nancy Cedex, France
}

\begin{abstract}
Arsenic can be selectively removed from water through adsorption on a natural manganese oxide. This paper presents some of the key parameters controlling such a process. Both production and regeneration steps were studied and the influence of three main controlling parameters was put to light. The water $\mathrm{pH}$ greatly influenced the adsorption capacity. Low water $\mathrm{pH}$ highly improved the treatment. The adsorption being under mass transfer limitation flow rate influence was measured and optimization solutions were proposed. Finally, the impact of the regeneration procedure was evaluated on the adsorbent stability. It gave good arsenic elution results but the caustic elution step generated fine particles that could not be avoided. The following neutralization could however be adjusted in order to minimize further adsorbent dissolution.
\end{abstract}

\section{KEY WORDS}

adsorption process, arsenic, drinking water treatment, manganese oxide

\section{INTRODUCTION}

Arsenic, a well-known toxic element, has proved carcinogenic at low ingestion rate (Basu et al., 2001). Hence its presence in drinking water even at low concentration is a threat for human health. Besides its occurrence in drinking water of some parts of the world, mainly in Asia, leads to alarming public health problems (Masud, 2000). Many regulatory authorities throughout the world (EC, EPA) have therefore followed the World Health Organization recommendations and lowered the critical concentration for total arsenic in drinking water from 50 to $10 \mu \mathrm{g} \mathrm{L}^{-1}$. New highly efficient treatments are then necessary to meet the standards and adsorption processes are particularly attractive. In natural waters, arsenic is mainly found under two oxidation states: +III and +V. Most adsorbent can only deal with As $\mathrm{V}$ and a pre-oxidation state is then necessary. Manganese oxides can however readily oxidize As III into As V and adsorb it (Thanabalasingam and Pickering, 1986; Bajpai and Chaudhuri, 1999).

The aim of this paper is to present some key points for the design of such an adsorption process. The main governing parameters of the process are of three kinds. First, the process performances obviously depend on the adsorbent quality. This point won't be discussed. The second point to take into consideration is the water composition. The ionic composition as well as $\mathrm{pH}$ may both influence adsorption capacity and/or selectivity. Previous work (Ouvrard et al., 2001) has proved that though other oxianions (phosphate, sulfate, bicarbonate) could be adsorbed on the material, arsenic remains highly preferred and no competition occurs. We will see however here that arsenate adsorption strongly depends on the $\mathrm{pH}$. The process efficiency is then highly linked to the water $\mathrm{pH}$. Third, the 
process control parameters influence needs to be assessed. The process work on a cycling basis, adsorption is followed by a regeneration step. We will more focus on the flow rate influence on the adsorption and we will evaluate the regeneration impact on the material stability.

\section{MATERIALS AND METHODS}

The adsorbent is a natural manganese oxide whose main characteristics are presented in table 1.

All solutions were prepared with analytical grade salts of sodium arsenate and deionized water.

Two main experimental procedures were used: batch and column systems. Batch experiments were performed in $125 \mathrm{ML}$ polyethylene vessels. Column experiments were conducted in glass column Pharmacia type (internal diameter $10 \mathrm{~mm}$ ) fed with a plug flow pump. Both $\mathrm{pH}$ and conductivity were measured on-line at the outlet and fraction collection enabled further ion analysis by AA or ion chromatography.

Table 1 Adsorbent main characteristics

\begin{tabular}{|c|c|c|c|}
\hline Specific surface & Zero point & \multicolumn{2}{|c|}{ Elemental composition (\%w) } \\
\cline { 3 - 4 } area $\left(\mathrm{m}^{2} \mathrm{~g}^{-1}\right)$ & of charge & $\mathrm{MnO}_{2}$ & $\mathrm{Al}_{2} \mathrm{O}_{3}$ \\
\hline 16 & 4.7 & 70.9 & 5.92 \\
\hline
\end{tabular}

\section{pH INFLUENCE ON ADSORPTION}

\section{Capacity Evolution With pH}

Batch experiments were conducted to evaluate $\mathrm{pH}$ impact on capacity. The results presented in figure 1 clearly showed that the adsorption capacity for arsenic greatly increased as $\mathrm{pH}$ decreased. This behavior followed the electrostatic evolution of the solid/solution system. Indeed, in this $\mathrm{pH}$ range arsenate was always under anionic form whereas the surface charge of the oxide went from positive to negative values as the $\mathrm{pH}$ increased with a zero point of charge at 4.7. Below this $\mathrm{pH}$ value, electrostatic interactions promoted adsorption and above they were opposed to the solute approach to the surface. Though these phenomena explained the tendency observed on the capacity evolution as a function of $\mathrm{pH}$, they were not the only interactions involved in arsenate adsorption on the manganese oxide since it occurred even in repulsive electrostatic conditions.

\section{Water pH: A Key Parameter To The Treatment Efficiency}

The major effect of $\mathrm{pH}$ on arsenate adsorption capacity made it a key parameter for the treatment capacity estimation. Indeed, depending on the water $\mathrm{pH}$ the adsorption capacity seemed to be highly modified and this parameter should therefore be taken into account for installation dimensioning.

In order quantify more precisely water $\mathrm{pH}$ effect, two column adsorption experiments were run with solutions at the same arsenic concentration but whose $\mathrm{pH}$ had been modified with acid addition. The final conditions are reported in table 2 and the breakthrough curves of these two solutions are plotted in figure 2. They led to arsenic capacities of 4.69 and 2.66 $\mu \mathrm{mol} \mathrm{g}{ }^{-1}$ for the respective $\mathrm{pH}$ values of 6.86 and 7.47 . These results confirmed batch observations: the $\mathrm{pH}$ decrease by less than a unit led to a capacity increases of $76 \%$ at this arsenic concentration.

Combining results from batch and column experiments arsenic adsorption isotherms for two different $\mathrm{pH}$ were evaluated. They could be roughly well represented by a Langmuir type model whose parameters are presented in table 3 . These results could then be used 
to evaluate the treatment capacity for an arsenic concentration close to the one found in natural waters: $0.27 \mu \mathrm{mol} \mathrm{L}^{-1}\left(20 \mu \mathrm{g} \mathrm{L}^{-1}\right)$. Results then led to the respective adsorption capacity of 0.3 and 0.6 for 7.47 and $6.86 \mathrm{pH}$. This put to light how sensitive the treatment capacity was to the water $\mathrm{pH}$ and this parameter clearly appeared as a key one for installation dimensioning.

Table 2 Experimental conditions of column adsorption experiments

\begin{tabular}{|c|c|c|}
\hline Experiment & {$[\mathrm{As}](\mathrm{mM})$} & $\mathrm{pH}$ \\
\hline 1 & 0.67 & 6.86 \\
\hline 2 & 0.67 & 7.47 \\
\hline
\end{tabular}

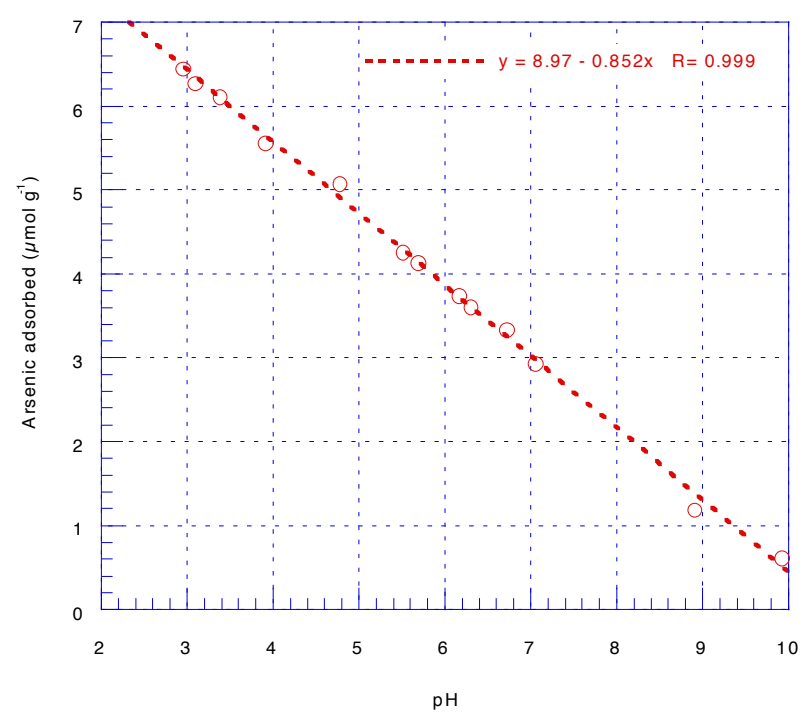

Figure 1 Arsenic adsorption capacity as a function of equilibrium $\mathrm{pH}$ for a batch system of $100 \mathrm{ML}$ solution, $2 \mathrm{~g}$ adsorbent, As initial concentration $5 \mathrm{mg} \mathrm{L}^{-1}$.

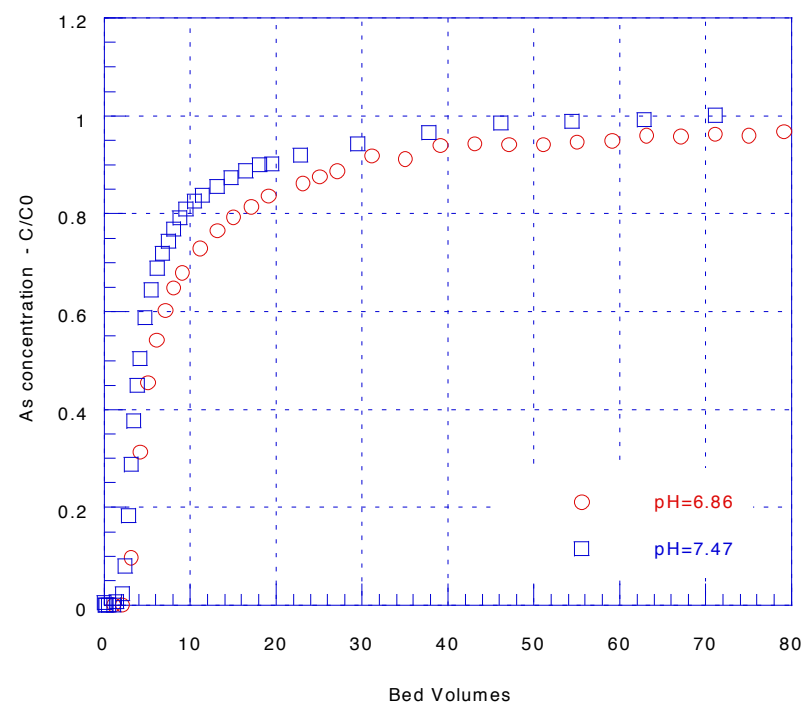

Figure 2 Arsenic breakthrough curves for solutions 1 and 2 (cf. Table 2).

Bed volume $5 \mathrm{ML}$, flow rate $25 \mathrm{ML} \mathrm{h}^{-1}$. 
Table 3 Experimental conditions of column adsorption experiments

\begin{tabular}{|c|c|c|}
\hline $\mathrm{pH}$ & $\mathrm{q}_{\max }\left(\mu \mathrm{mol} \mathrm{g}^{-1}\right)$ & $\mathrm{K}_{\mathrm{L}}\left({\left.\mathrm{L} \mu \mathrm{mol}^{-1}\right)}^{-1}\right.$ \\
\hline 6.86 & 2.3 & 0.56 \\
\hline 7.47 & 4.7 & 0.55 \\
\hline
\end{tabular}

\section{MASS TRANSFER LIMITATION}

Kinetic experiments run in batch reactors have proved arsenic adsorption rate was controlled by mass transfer through intraparticle diffusion. A Fick law type could easily represent these kinetic limitations. As a consequence breakthrough curve forms are highly sensitive to both flow rate and adsorbent particle size. The smaller the flow rate and the particle size the more the breakthrough point of the curve was delayed. In real operating conditions, the adsorbent particle size cannot be drastically reduced, to prevent excessive head loss. Then, we focused here on the flow rate influence and the way its value could be optimized on an economic basis.

\section{Flow Rate Influence}

Breakthrough curves of a $50 \mathrm{mg} \mathrm{L}^{-1}$ arsenate solution were measured for three different empty bed residence times (EBRT): 0.60, 12 and 60 minutes. The results presented in figure 3 showed the following tendencies:

- The breakthrough point was delayed as the EBRT increased,

- The curve was more broadening with longer tailing as the EBRT decreased.

These results clearly illustrated the effect of mass transfer limitations.

The experimental breakthrough curves were modeled, by mean of a computer code developed in our laboratory, combining both transport equation and mass transfer limitations described with a Fick law equation (Chue, 1991). A very good agreement between experimental and modeled results was found as presented figure 3 . This code was then further used as an optimization tool.

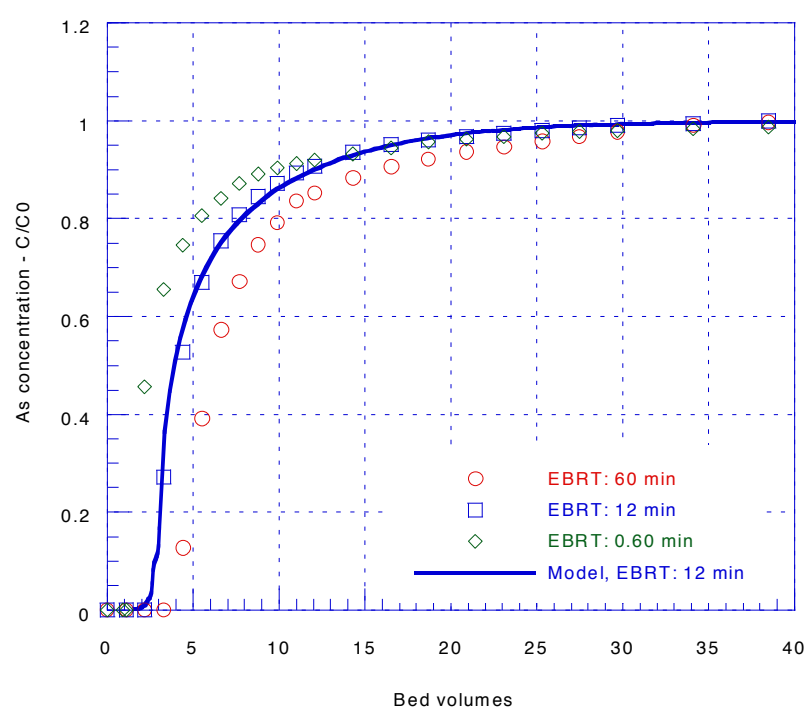

Figure 3 Arsenic breakthrough curves for three EBRT. Bed volume $5 \mathrm{ML}$, [As] $=50 \mathrm{mg} \mathrm{L}^{-1}$.

\section{Optimization Tool}

For the treatment application, the later the breakthrough point the higher the effective capacity since the treatment is stopped when the limit concentration is reached (e.g. $10 \mu \mathrm{g}$ $\left.\mathrm{L}^{-1}\right)$. Small flow rates greatly increased the treatment effective capacity, but to keep the 
same production rate, the column size needed to be increased. A compromise had then to be found between capacity profit and investment cost.

The breakthrough point of a solution containing $100 \mu \mathrm{g} \mathrm{L}^{-1}$ As was calculated with the model and is presented figure $4 \mathrm{~b}$. The obtained curve confirmed that the effective capacity, number of bed volumes produced at the breakthrough point, increased when the EBRT increased. However at the same time, for a given column size, the water production rate decreased (Figure 4a). Table 4 presents the performance of an installation for two different EBRT: 10 and 20 minutes. In the second case, to keep the same production rate, the column size should be twice that in the first one, which means a higher investment cost. However in that second configuration, regeneration would be less frequent and running costs would therefore be reduced.

Depending on the water production required and the arsenic concentration of the water to be treated, a real global cost optimization could be performed this way using the model developed, in which the EBRT in the column and the installation size should to be adjusted.

Table 4 Comparison of two production conditions for a nominal water flow rate of $6 \mathrm{~m}^{3} \mathrm{~h}^{-1}$

\begin{tabular}{|l|c|c|c|c|}
\hline & EBRT $(\mathrm{min})$ & Flow rate $(\mathrm{BV} / \mathrm{min})$ & Column size $\left(\mathrm{m}^{3}\right)$ & Effective capacity (BV) \\
\hline Case 1 & 10 & 0.1 & 1 & 220 \\
\hline Case 2 & 20 & 0.05 & 2 & 390 \\
\hline
\end{tabular}
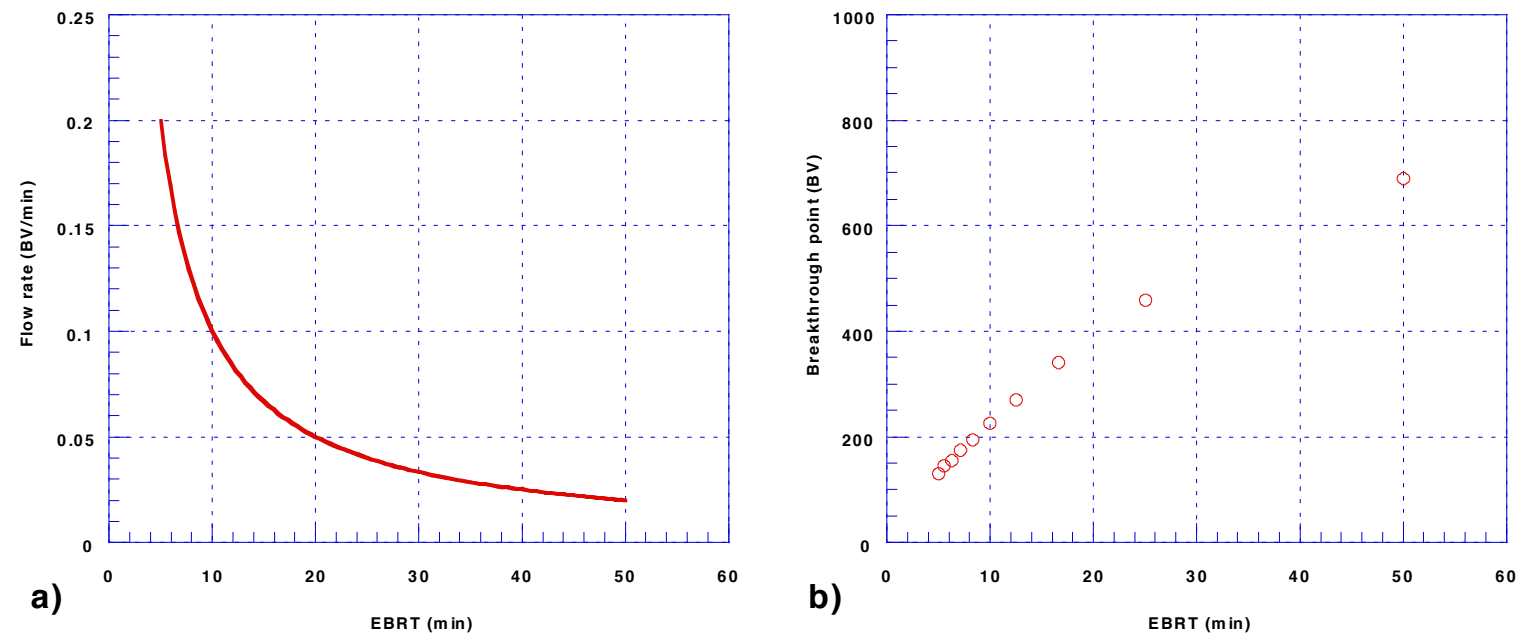

Figure 4 Influence of the EBRT on a) water production rate and b) effective capacity for a $100 \mu \mathrm{L}^{-1}$ As solution as given by the model.

\section{REGENERATION CONTROL}

The regeneration procedure is in four steps (Jauffret, 1998):

- Arsenic elution with concentrated caustic soda,

- Washing to remove porous water still highly loaded in arsenic,

- Acid neutralization,

- Final washing.

The two first stages are efficient enough for total arsenic recovery, however they are quite chemically aggressive for the adsorbent. The following neutralization step may also lead to some troubles. In order to assess the respective effects of each step, two main points regarding the adsorbent stability were investigated:

- Fine production,

- Adsorbent dissolution. 


\section{Fine production}

The production of fine particles is a drawback in the process and must be avoided. The main mechanisms of fines creation needed to be found in order to prevent it or reduce its effects.

Attrition experiments were conducted with the natural manganese oxide. $2 \mathrm{~g}$ of adsorbent were stirred in batch reactors with different solution types: caustic soda or water of different ionic strengths (Table 5) and the mass of fine particles generated was determined. The results presented in figure 5 showed that the production of fine particles was mainly due to the effect of caustic soda. It was not influenced by the washing solution type. In the process, the caustic soda elution was therefore responsible for the production of the fine fraction. This first step is essential for arsenic elution and cannot be avoided. The regeneration procedure should then be adapted in order to remove the created fine fraction, for instance in including a high flow rate counter-current washing.

Table 5 Experimental conditions of the attrition tests on the natural manganese oxide

\begin{tabular}{|c|c|c|c|c|c|}
\hline Sample & 1 & 2 & 3 & 4 & 5 \\
\hline Stirring solution & $\mathrm{NaOH} 0,5 \mathrm{~N}$ & $\mathrm{NaOH} 0,5 \mathrm{~N}$ & $\mathrm{NaOH} 0,5 \mathrm{~N}$ & $\mathrm{NaCl} 0,5 \mathrm{~N}$ & water \\
\hline Washing solution & water & water & $\mathrm{NaOH} 0,5 \mathrm{~N}$ & water & water \\
\hline
\end{tabular}

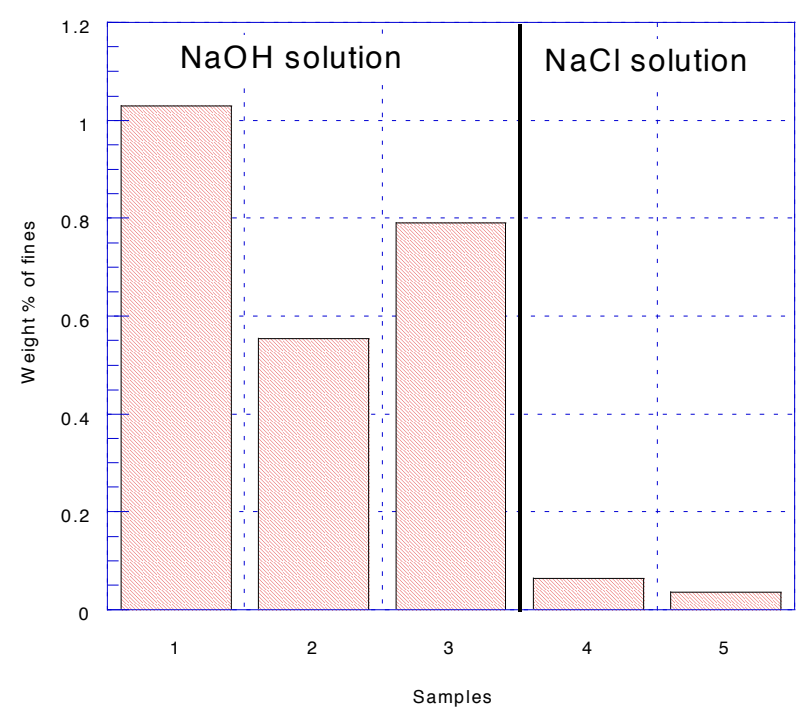

Figure 5 Fine production quantities for different solutions.

\section{Adsorbent dissolution}

To assess the chemical stability of the adsorbent during regeneration, further experiments were conducted in batch reactors. We quantified the amount of dissolved manganese produced for a wide range of equilibrium $\mathrm{pH}$ : 3-11. The results presented in figure 6 showed the following tendencies:

- In alkaline conditions, manganese dissolution was low, and the concentration remained steady on the entire $\mathrm{pH}$ range. It was probably the consequence of solid/liquid equilibrium, confirmed by the presence of colloids in the suspension.

- In acidic conditions, for $\mathrm{pH}$ lower than 5, the dissolved manganese concentration increased dramatically as the $\mathrm{pH}$ decreased illustrating the fragility of the adsorbent in acidic solutions.

These observations led to some recommendations for the regeneration control. First, the colloids formed under alkaline conditions were most certainly the premises to fine formations put to light in the previous paragraph. Second, the high fragility of the 
adsorbent under acidic conditions indicated that the neutralization step should be carefully controlled. Indeed, if the amount of acid used is overestimated, a systematic degradation of the adsorbent could occur.

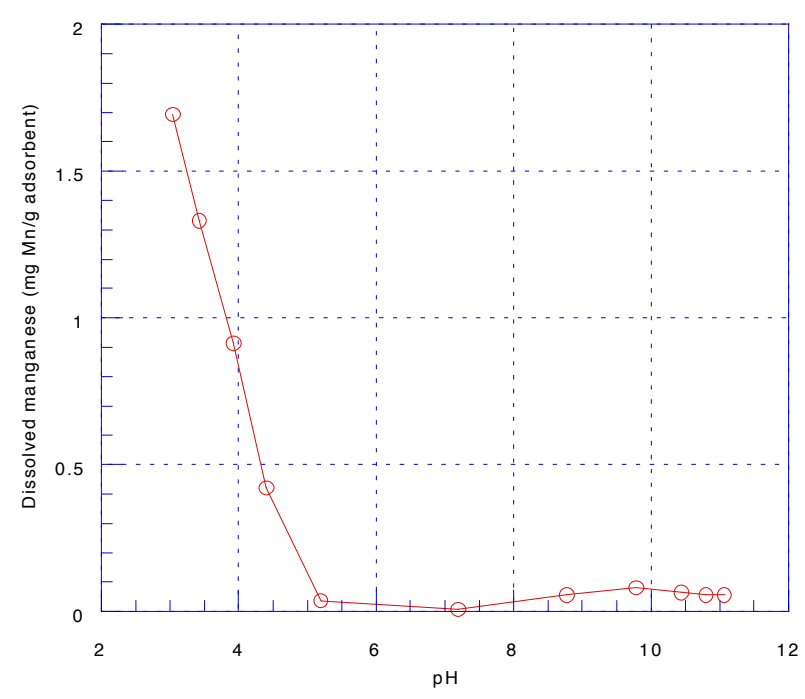

Figure 6 Adsorbent dissolution as a function of equilibrium $\mathrm{pH}$

\section{CONCLUSION}

Adsorption of arsenic on a natural manganese oxide is a promising solution treat water contamination. This work has put to light some essential parameters for installation design. Both production and regeneration steps were considered and the following results were drawn:

- The water $\mathrm{pH}$ highly influenced treatment capacity even in the small range of natural waters. Low $\mathrm{pH}$ improved adsorption capacity and its value clearly appeared as a key parameter.

- Adsorption being controlled by mass transfer, breakthrough curves were sensitive to flow rate. This parameter could then modify the effective capacity of the treatment and enters as a major criterion for the installation size choice.

- Life time of the process is governed by the regeneration efficiency. The procedure chosen gave good arsenic elution results but this elution step formed fine particles that had to be removed. The following neutralization step could also lead to adsorbent dissolution.

\section{REFERENCES}

Bajpai S. and Chaudhuri M. (1999). Removal of arsenic from groundwater by manganese dioxide-coated sand. J. Environmental Engineering, 125 (8), 782-784.

Basu A., Mahata J., Gupta S. and Giri A.K. (2001). Genetic toxicology of a paradoxical human carcinogen, arsenic: a review. Mutation Research, 488, 171-194.

Chue K.T. (1991). Dynamique de l'électradsorption-désorption en lit fixe. PhD Dissertation of Institut National Polytechnique de Lorraine, Nancy, France.

Jauffret $\mathrm{H}$. (1998). Elimination de certains ions à l'aide de sable manganifère. Cahiers de l'Association Scientifique Européenne pour l'Eau et la Santé, 3 (1), 85-90.

Masud K. (2000). Arsenic in groundwater and health problems in Bangladesh. Water Research, 34 (1), 304-310. 
Ouvrard S., Simonnot M.O. and Sardin M. (2001). Removal of arsenate from drinking water with a natural manganese oxide in the presence of competing anions. Water Science and Technology: Water Supply, 1 (2), 167-173.

Thanabalasingam P. and Pickering W. F. (1986). Effect of $\mathrm{pH}$ on interaction between As(III) or As(V) and manganese(IV) oxide. Water, Air and Soil Pollution, 29, 205-216.

\section{CONTACT}

Marie-Odile Simonnot, Laboratoire des Sciences du Génie Chimique, 1 rue Grandville, BP 451, 54001 Nancy Cedex, France.

Tel: (+33) 383175260

Fax: (+33) 383322975

Email: Marie-Odile.Simonnot@ensic.inpl-nancy.fr 